This is an electronic reprint of the original article. This reprint may differ from the original in pagination and typographic detail.

Author(s): Luoma-aho, Vilma; Canel, Maria-Jose

Title: $\quad$ Public Sector Reputation

Year: $\quad 2016$

Version:

Please cite the original version:

Luoma-aho, V., \& Canel, M.-J. (2016). Public Sector Reputation. In C. E. Carroll (Ed.), SAGE Encyclopedia of Corporate Reputation (pp. 597-600). SAGE Publications. https://doi.org/10.4135/9781483376493.n229

All material supplied via JYX is protected by copyright and other intellectual property rights, and duplication or sale of all or part of any of the repository collections is not permitted, except that material may be duplicated by you for your research use or educational purposes in electronic or print form. You must obtain permission for any other use. Electronic or print copies may not be offered, whether for sale or otherwise to anyone who is not an authorised user. 


\section{Public SECTOR RePUTATION}

Public sector organizations (also referred to as authority, governmental and public administration organizations) refer to organizations and institutions aimed at providing services needed by citizens in societies. Public sector organizations are social systems of groups and individuals that have the authority to work together to serve current public needs as well as to collect from citizens the required resources. Authority can be described as legitimated power, and public sector organizations need some form of public consent in democratic settings (or coercion in totalitarian regimes) to operate. Public sector organizations operate on several levels: national, regional and municipal, and they have-both politically elected as well as fixed officials as public servants.

An organization is considered public if it is mostly "owned" by the "public" (the citizens) and functions with state funding, for example finances collected via taxes. The needs of users for public services are increasingly tested, and there is a trend of consumerization of public sector services. There is a global emphasis on private rather than public service provision, causing more public sector organizations and public services to be questioned, and increasing the amount of 'user pays' services. Moreover, many public sector organizations are mature in age, and facing recent reforms and mergers, as they are restructured to better meet changing citizen needs. As public funding is globally decreasing, public sector organizations are increasingly funded by external sources including project- and development based funding from multinational entities such as UN, NATO or the European Union or charging service fees from citizens. The degree to which a public sector organization serves citizens depends on the societal setting, and the responsibilities of public sector organizations range from almost providing full service (Nordic Welfare states) to providing some general societal goods and benefits to those in need (like for instance the US and most European countries).

Communication is worldwide showing to be vital for public sector organizations. Public sector organizations globally tend to have a reputation for excess bureaucracy and inefficiency of operations. Citizen tend to be critical overall toward the public sector, but for individual services their evaluations often are better. The reputation of public sector organizations has developed over time, and impression of public sector organizations are plagued by negative connotations 
despite their vital role of guaranteeing safety both inside and outside the society. Approaching reputation in the public sector entails complexities in terms of goals, needs, audiences, definition and resources which are different from the private sector. First, the environment is political, what affects resources, personnel and goals. Public sector structures are more complex, diverse and uncertain about objectives and decision-making criteria. The public sector is less open to market competition with less incentive to reduce costs and less concern with consumer preferences. Second, public sector organizations are more constrained by legal and regulatory frameworks than corporations; they are more subject to public scrutiny and required to have a high degree of accountability to constituencies. Finally, the diversity and multiplicity of publics and stakeholders exceeds that of corporations (see Canel \& Sanders 2013). In sum, public sector organizations have to operate under different constrains, and to balance political guidelines, national guidelines, international cooperation, ideologies management, the bureaucratic culture of administration and current citizen and customer feedback.

In terms of reputation, both who stakeholders are and how they experience and judge the public sector organizations and services are issues to be mentioned. Public sector organizations are often assessed based on public service quality. Contribution of most public sector organizations is hard to be fairly assessed by citizens. In fact, what constitutes a good public service is a challenging question, but literature attempts to establish different principles, and they often include high quality of services, transparency and efficiency as well as rectification of errors. Public services are often assessed via measuring the perceived quality of a service as comparable to the product-quality reviews, and the focus has been on whether public services meet the needs in society. However, research has to explore the complex dynamic of indirect causal relationships between public organizations' achievements, communication performance, citizens' satisfaction and trust (James, 2009; 2011).

The responsibilities of public sector organizations range from political, legal, managerial and social responsibilities along with emerging citizen and employee needs. As the end-users represent a wide variety of individual needs and expectations, public sector organizations are often specialized into regions or areas of expertise, and must balance multiple goals. Among their areas of responsibility are infrastructure, livelihood, transportation, education and healthcare of the citizens. 
When categorized according to amount of contact with the public and degree of service fee van der Hart (1991) distinguishes indirect payment services (criminal justice, emergency services), and indirect contact services (central governments and departments), where reputation can best be measured among the different stakeholders it serves instead of individual citizens. As for the direct payment services (housing, postal services, transportation) and direct contact services (customs, excise), their reputation is more comparable to the corporate reputation, and can benefit from application of more general reputation measures aimed at customers. Laing (2003, 438) makes public services into a continuum based on the service beneficiary: from social benefits to private benefits (Figure 1) Accordingly, the stakeholder among which service reputation will matter most is divided between professional/expert such as analysts and other authorities and citizen/consumer/end user judgement, and the middle ground remains the most challenging for reputation measurement for it is a combined judgment.

Public Service for social benefits

Reputation: professional judgement

Customs \&

excise

Image 1. The spectrum of public services reputation
Trust and reputation in the public sector

Image 1. The spectrum of public services reputation judgment (adapted from Laing, 2003; 438).

Underneath reputation in the public sector is trust. Citizen trust in public sector organizations is central, as it enables and authorizes the organizations to function. Trust in public sector organizations is globally low, with citizens reporting problems with transparency and bureaucracy. International rankings have been established to show which countries have the highest amount of trust in public sector organizations and government, and despite the volatile nature of trust, reputation seems more stable.

However, as research has shown, (dis)trust is not easily explainable, for trust in public sector organizations is multi-causal, contingent and contextual. Variables that explain (dis)trust vary: personal experiences, satisfaction with government performance, satisfaction with public services, party affiliation, etc. Identifying causes is important to determine practical implications for public sector reputation management. Also, facing a multitude of needs, public sector 
organizations and their services are often very complex and hierarchic, known for bureaucratic procedures and inefficiency. Public sector organizations serve a range of different constituents from politics, the media and individual citizens, international diplomacy and often have limited budgets and resources dedicated to communication. According to the theory of generalized trust, individual citizen experiences of public sector organizations and institutions make the basis on which citizens judge and decide whether people in society in general can be trusted, making public sector trust and reputation valuable not only for individual services but the society at large.

When compared to corporate reputation, Luoma-aho (2007) has distinguished an additional factor that shapes reputation of public sector organizations but is not apparent for corporations. She titles this the authority functions-factor, and it consists of views of how open the organization is for citizen engagement, how well it listens to citizen needs, how dynamic, conversing and flexible (or closed, dictating and bureaucratic) and citizen-oriented the organization is. All these are believed to contribute to the public sector organizations' reputation.

As for the ideal reputation for public sector, neutral reputation and neutral levels of trust have been suggested (Luoma-aho, 2007). Public sector organizations often lack the financial resources and personnel time needed to cultivate an extremely positive reputation, and negative experiences could cause a significant drop in a too ambitious reputation. As reputation is a promise of future behavior, public sector organizations' reputation should be kept at a level that is sustainable.

Public sector reputation has been understood as a specific construct different from that of corporations. More vulnerable to societal influences and settings, the reputation of public sector organizations is influenced not only by the service type, but by the reputation of sector. In fact, the type of organization matters for reputation: administration and regulation organizations are perceived as more bureaucratic than those organizations providing direct services (Luoma-aho, 2008). The strong role of bureaucracy in reputation of public sector organizations dates back to the industrial era, when public administration was based on rationality and hierarchy. In this traditional setting, citizen engagement and participation in the decision-making processes and services was minimal.

Globally there is an emerging need to improve public services and modernize the organizations providing them. As studies on citizen satisfaction have noted, though citizens in 
general may be dissatisfied with public services, when it comes to rating their personal experiences of services, satisfaction rises. Reputation of public sector organizations may hence be negative on the sector level, but individual services may yet have a positive reputation.

\section{Criticisms of Reputation of Public Sector Organizations}

All investments that public sector organizations make are under scrutiny, and the biggest challenge of reputation in the public sector has been to make the case for the role of reputation. Some have argued that there is no need to communicate about public services, and their reputations should be formed though actions alone. Moreover, critics have also questioned whether it actually matters what kind of reputation public sector organizations have, as they are often monopolies and non-selection based, so the comparative aspect of reputation is missing. On the other hand, there is the claim that above mentioned low levels of trust are due to both wrong managed as well as communicated organizations, and that better reputed public organizations would be beneficial to society: trustful public organizations maintain and attract business, increase legitimacy, guaranty fulfillment of public policies without the need to increase coactivity, enhance public participation, empower citizens and increase engagement.

\section{Implications for reputation management in the Public Sector}

The following implications can be drawn from literature on both reputation management and expectations:

- Reputation of public services is a different construct from the reputation of public sector organizations

- Reputation of political and public leaders that lead governments and public administrations is a different construct from public sector or services themselves

- The public services aim ranges from social benefits to individual benefits, and measuring reputation changes accordingly from experts/professional judgment to citizen judgment 
- Neutral levels of trust and reputation have been suggested as ideal for public sector organizations' reputation as to best meet existing resources

- Since public sector reputation operates in a political environment, different constraints affecting structures, resources, personnel and goals need to be taken into account for reputation management

- Managing reputation of public sector organizations is an emerging research area with practical implications that deserves deeper explorations of related intangible assets such as legitimacy, engagement, institutional culture, institutional social responsibility, social capital, transparency, relationship building and trust.

Vilma Luoma-aho \& Maria-Jose Canel

See also Public sector communication, Trust; Citizen satisfaction; Expectation management; Institutions

\section{FURTHER READINGS}

Canel, M.J. \& Sanders, K. (2012). Government communication: An emerging field in Political Communication research. In H. Semetko \& M. Scammel (Eds.), Handbook of Political Communication (pp. 85-96). Sage.

van der Hart, H. (1990). Government Organizations and their Customers in the Netherlands: Strategy, Tactics and Operations. European Journal of Marketing, 24(7), 31-42.

James, O. (2009). Evaluating the expectations disconfirmation and expectations anchoring approaches to citizen satisfaction with local public services. Journal of Public Administration Research and Theory, 19(1), 107-123.

James, O. (2011). Performance measures and democracy: Information effects on citizens in field and laboratory experiments. Journal of Public Administration Research and Theory, 21(3), 399-418. 
Laing, A. (2003). Marketing in the Public Sector: Towards a Typology of Public Services. Marketing Theory, 3, 427-445.

Luoma-aho, V. \& Mäkikangas, M. (2014). Does public sector merger (re)shape reputation? The International Journal of Public Sector Management, 27(1), 39-52.

Luoma-aho, V. (2008). Sector reputation and public organizations. International Journal of Public Sector Management, 21(5), 446-467.

Luoma-aho, V. (2007) Neutral reputation and public sector organizations. Corporate Reputation Review, 10(2), 124-143. 